\title{
KAJIAN PENGGUNAAN SINAR MATAHARI UNTUK PENGKONDISIAN UDARA RUANGAN MENGGUNAKAN BATU ALAM PULAU TIMOR SEBAGAI PENYERAP PANAS PADA SYTEM DINDING TROMBE
}

\author{
Aris Palinggi ${ }^{1}$, Oktovianus D. Rerung ${ }^{2}$, Edwin P.D. Hattu ${ }^{3}$ \\ 1,2 Jurusan Teknik Mesin, Politeknik Negeri Kupang \\ E-mail : apapaling1@gmail.com \\ 1,2 Jurusan Teknik Mesin, Politeknik Negeri Kupang \\ E-mail : edwin_hattu@yahoo.com \\ ${ }^{3}$ Jurusan Teknik Mesin, Politeknik Negeri Kupang \\ E-mail: s55_mr@yahoo.co.id
}

\begin{abstract}
Abstrak
Penggunaan energi fosil yang semakin meningkat pada akhirnya menyebabkan pemanasan global, oleh sebab penggunaan energi yang bersih seperti energi matahari sangat diperlukan. Energi matahari dapat digunakan untuk mendinginkan ruangan yaitu dengan sistem dinding Trombe. Dinding Trombe banyak digunakan dengan posisi vertikal di negara-negara sub tropis. Tujuan pada penelitian ini adalah untuk mengetahui kondisi suhu ruangan setelah diterapkan sistem dinding Trombe. Metode yang digunakan adalah penggunaan batu alam Pulau Timor sebagai penyerap panas dan dilakukan dengan alat simulasi berupa kotak. Perhitungan panas dilakukan dengan pemasangan sensor panas dan software berupa Adriuno Uno dan Ashare. Pengambilan data setiap 5 menit dari jam 09.00 sampai jam 21.00. Penelitian dilakukan dengan memperbandingkan kondisi udara (temperatur) udara Luar ruangan dengan ruangan tanpa dinding Trombe, dan ruangan dengan dinding Trombe vertikal,. Kondisi udara ruangan tersebut juga akan dibandingkan dengan kondisi standar kenyamanan udara untuk aktivitas manusia. Hasil yang didapatkan menunjukkan bahwa penggunaan dinding Trombe di daerah tropis akan membuat ruangan lebih sejuk Penggunaan dinding Trombe Horizontal mampu menurunkan suhu lebih rendah dibanding vertikal. Semua data yang didapatkan menunjukkan kondisi ruangan dengan dinding Trombe masih belum memenuhi syarat kenyamanan manusia sebab pada saat pengambilan data kondisi suhu di NTT sedang musim panas.
\end{abstract}

Kata kunci: Sinar Matahari, Dinding Trombe, Batu Alam.

\section{PENDAHULUAN}

Penggunaan energi fosil yang semakin meningkat berakibat terjadinya fenomena pemanasan global, di mana temperatur bumi semakin panas. Hal ini diantisipasi dengan penggunaan sumber energi alternatif terbarukan, seperti energi matahari. Energi matahari dapat digunakan secara langsung maupun secara tidak langsung dengan mengubah bentuknya menjadi energi lain. Salah satu bentuk pemanfaatan energi matahari secara langsung adalah dengan menggunakan dinding Trombe. Dinding Trombe difungsikan sebagai penyimpan panas, yang nantinya digunakan untuk menciptakan perpindahan energi dan massa secara pasif dengan memanfaatkan energi radiasi matahari.

Nusa Tenggara Timur ( NTT ) merupakan daerah yang iklimnya tropis sehingga dikenal dua musim yaitu musim panas dan musim hujan. Musim panas di NTT berlangsung lebih lama dari musim hujan sehingga sangat mempengaruhi cuaca di mana saat musim panas suhu kadang sangat tinggi bahkan mencapai $37^{\circ} \mathrm{C}$ atau lebih dan ini sangat mempengaruhi kenyamanan masyarakat sehingga perlu memanfaatkan sinar matahari yang melimpah untuk pengkondisian ruangan.

Saat ini pemerintah pusat khususnya Presiden Jokowi giat membangun daerah yang belum maju seperti NTT dengan membangun infrastruktur pendukung sekaligus mencari potensi daerah baik alam maupun manusia yang bisa dikembangkan. Salah satu potensi NTT dari sumber daya alam yaitu batu alam berupa marmer yang terdapat banyak di Pulau Timor dan sudah dikelola di Kabupaten Timor Tengah Selatan. Batu alam ini banyak digunakan sebagai penghias dinding rumah maupun bangunan lainnya. Dengan pemanfaatan batu alam lokal yang mulai banyak maka perlu dicari tentang pengaruhnya pada pengkondisian udara 
ruangan secara alami yaitu dengan dinding Trombe

Beberapa penelitian sudah dilakukan untuk memanfaatkan dinding Trombe guna pengkondisian udara ruangan namun kebanyakan menggunakan beton atau campuran yang lain, sedangkan untuk wilayah NTT pemanfaatan bahan alam lokal untuk dinding Trombe belum dilakukan.

\section{DINDING TROMBE}

Prinsip kerja sistem dinding Trombe adalah menggunakan gabungan sistem kaca dan dinding penyimpan panas, radiasi matahari menembus kaca dan memanaskan penyimpan panas, penyimpan panas ini akan memanaskan celah antara dinding dan kaca, sehingga memungkinkan adanya perpindahan energi dan massa pada ruangan. Dinding Trombe dapat berbahan semen atau batu. Dinding Trombe ini banyak digunakan untuk pemanasan ruangan di daerah sub tropis, dengan posisi dinding vertikal menghadap ke arah utara/selatan. Pada daerah tropis yang memerlukan pendinginan ruangan, penggunaan dinding Trombe perlu diteliti, disebabkan karena perbedaan posisi matahari yang cenderung berada di atas, maka ada kemungkinan perubahan posisi dinding dari posisi vertikal ke horisontal. Di samping itu penggunaan dinding vertikal akan menghalangi pandangan ke luar.



Gambar 1. Prinsip Kerja Dinding Trombe

Khedari, dkk (1997) telah melakukan penelitian tentang ventilasi alami untuk perumahan dengan menggunakan dinding Trombe. Penelitian ini dilakukan dengan menggunakan dinding Trombe yang dicat hitam dan dhadapkan ke arah selatan, dengan ketebalan $8 \mathrm{~cm}$ dengan lebar $1 \mathrm{~m}$. Pada penelitian ini yang divariasikan adalah tinggi dari dinding Trombe dan celah antara dinding
Trombe dengan penutup kaca. Hasil dari penelitian didapat bahwa dinding Trombe mempunyai performa ventilasi yang baik pada tinggi dinding $2 \mathrm{~m}$ dan lebar celah $14,5 \mathrm{~cm}$. Ong, dkk (2003) telah melakukan penelitian tentang cerobong matahari (solar chimney). Yang diamati pada penelitian ini adalah pengaruh variasi celah udara dan radiasi matahari terhadap kecepatan aliran udara di celah antara dinding dan kaca. Variasi lebar celah udara yang diteliti adalah 0,$1 ; 0,2$; dan $0,3 \mathrm{~m}$. Hasil penelitiannya adalah variasi kecepatan di celah udara $0,25-0,39 \mathrm{~m} / \mathrm{s}$ untuk radiasi surya di atas $650 \mathrm{~W} / \mathrm{m} 2$. Pada penelitian ini ditemukan juga bahwa tidak ada aliran balik pada seluruh variasi celah udara.

Febrita, Y. (2011) telah melakukan penelitian ventilasi solar chimney dengan membandingkan hasil penelitian yang dilakukan oleh Jyotirmay (2006), Nugroho (2006) dan Chitsomboon (2004), di mana pokok bahasan yang sama yaitu mengenai solar chimney ventilation. Perbandingan bertujuan untuk menentukan sampai sejauh mana parameter desain solar chimney ventilation dapat meningkatkan kecepatan udara di dalam bangunan pada daerah tropis lembap. Dari hasil penelitian ini menunjukkan bahwa penelitian Jyotirmay (2006) memiliki desain kecepatan angin yang paling tinggi yaitu meningkatkan arus ventilasi $36.85 \%$ pada radiasi matahari $949.53 \mathrm{~W} / \mathrm{M} 2$ dengan dimiringkan 45o. Koyunbaba, dkk (2012) telah melakukan penelitian tentang perbandingan performa sistem Trombe Wall penghangat ruangan dengan menggunakan variasi kaca, kaca ganda, dan semi transparan yaitu PV pada bagian eksteriornya



Gambar 2. Aplikasi pemasangan PV-Trombe Wall

Hasil penelitian dengan menggunakan PV panel sebagai Eksteriornya didapatkan maksimum temperatur 24oC pada jam 14.00 
dan radiasi yang diserap sebanyak 793,78 $\mathrm{W} / \mathrm{m} 2$ pada jam 13.00 tanggal 26 Februari. Efisiensi elektrik pada semi transparan solar sell di dapatkan sekitar 4.5\%. Wei, Sun. (2010) telah melakukan penelitian tentang performa dinding Trombe yang dikombinasikan dengan PV panel sebagai pelapis kaca pada eksteriornya dan menambahkan jendela di sampingnya dengan menghadapkan ke arah selatan. Penambahan jendela diharapkan dapat menambah pemanasan ruangan. Penelitian ini dilaksanakan pada musim dingin dengan letak garis lintang 37,86 o di negara China. Kemudian dimensi dari dinding Trombe yang dikombinasikan dengan PV Panel memiliki lebar 0,83 m, tinggi $2.6 \mathrm{~m}$, dan lebar celah antara panel surya dengan dinding Trombe adalah $0.18 \mathrm{~m}$. Pada jendela dipasang double kaca dengan ukuran $1.2 \mathrm{~m} \times 1.2 \mathrm{~m}$.

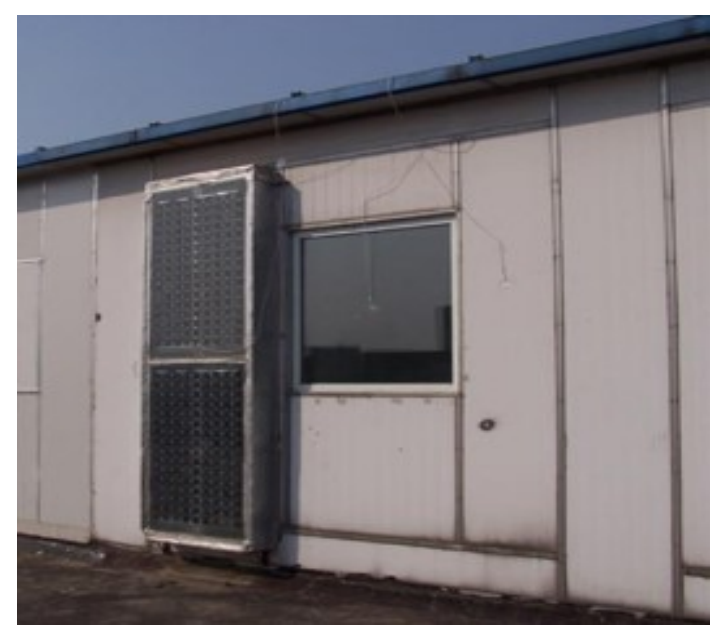

Gambar 3. Aplikasi PVTW dengan jendela pada bangunan

Penelitian ini menggunakan dua metode berbeda yaitu dengan simulasi dan data experimental. Hasil dari penelitian ini menunjukan bahwa desain dinding Trombe yang dikombinasikan dengan panel surya ditambahkan jendela pada sisi sampingnya dengan menghadapkan ke arah selatan pada musim dingin adalah terjadi pengurangan efisiensi thermal pada PVTW (PV-Trombe Wall) sebesar 27\%, kemudian dampak penambahan $\mathrm{PV}$ panel pada lapisan kaca dapat menurunkan efisiensi thermal sebesar $17 \%$. Total efisiensi pemanfaatan energy surya berkurang sebesar $5 \%$ dan Efisiensi elektrik yang didapat sebesar $11.6 \%$. Dinding Trombe merupakan sistem pemanas pasif yang diciptakan dan dipatenkan pada tahun 1881 oleh Edward Morse. Nama Trombe diambil dari salah satu insinyur Perancis dan arsitek yang dipopulerkan pada tahun 1964 yakni Felix Trombe dan Jacques Michel. Dinding ini dilapisi dengan kaca pada sisi external yang dipisahkan oleh celah udara. Lalu cahaya matahari yang tembus melewati kaca dalam spektrum elktromagnetik berupa sinar ultra violet akan diserap oleh dinding dan dipancarkan lagi dalam spektrum inframerah ke celah udara oleh dinding tersebut. Dinding Trombe menyimpan panas dari matahari dan melepaskan panas ke dalam ruangan atau bangunan di malam hari. Pada daerah tropis dinding Trombe dihadapkan ke arah utara untuk memaksimalkan paparan surya yang diterima dan bahan yang digunakan pada dinding ini terbuat dari bahan yang memiliki kapasitas panas tinggi atau bahan yang bersifat menyimpan panas seperti beton dan air. Di daerah tropis dinding Trombe digunakan sebagai pengkondisian udara untuk mendinginkan ruangan. Panas yang tersimpan dikondisikan supaya tidak masuk ke dalam ruangan namun panas tersebut dikondisikan agar memanaskan celah udara yang berada diantara dindingdan kaca. Perbedaan temperatur yang dihasilkan antara celah udara dengan ruangan menyebabkan perbedaan kerapatan massa udara. Panas tersebut akan membuat udara terdorong keluar pada celah sehingga kecepatan aliran pada ruangan meningkat.

\section{ENERGI MATAHARI}

Pemanfaatan energi matahari sudah berusia setua kehidupan itu sendiri, karena pada dasarnya tidak akan ada kehidupan di permukaan bumi tanpa energi matahari. Matahari telah digunakan untuk mengeringkan buah-buahan dan pangan lain serta pangan lain serta menguapkan air laut untuk mendapatkan garam. Pada awal abad dua puluh kolektor sinar matahari telah digunakan untuk memanaskan air. Karena harga bahan bakar fosil membumbung tinggi, pada pertengahan decade 70-an dan kemungkinan akan terus naik di waktu-waktu mendatang,energi matahari menjadi pusat perhatian sebagai salah satu sumber energi yang dapat diperbaharui (renewable). (Vries DKK, 2011) Beberapa bidang studi dan pemanfaatan energi matahari yaitu antara lain; konversi langsung energi matahari menjadi energi listrik, kolektor energi matahari suhu tinggi yang cocok untuk menggerakkan pembangkit daya, kolektor energi matahari plat datar suhu rendah, dan rancang bangunan yang menggunakan energi matahari secara 
pasif. Karena dalam waktu sehari energi matahari yang tersedia barangkali tidak mencukupi kebutuhan energi secara sempurna, maka tempat menyimpan kalor merupakan komponen yang tak terpisahkan dari suatu rancang bangun sistem energi matahari. (Reynold dan Perkins, 1983) Pancaran matahari merupakan radiasi elektromagnetik yang luar biasa banyak. Dalam kaitannya dengan sel surya yaitu perangkat pengkonversi radiasi matahari menjadi listrik, terdapat dua parameter penting dalam energi surya: pertama intensitas radiasi, yaitu jumlah daya matahari yang datang kepada permukaan per luas area, dan karakteristik spektrum cahaya matahari. (Vries DKK, 2011) 19 Energi thermal dari cahaya matahari adalah jenis energi yang terbarukan. Panjang gelombang radiasi matahari yang diterima di permukaan bumi berada pada daerah 0,29 sampai 2,5 $\mu \mathrm{m}$. Emisi radiasi dari matahari ke bumi menghasilkan intensitas radiasi surya yang hampir tetap di luar atmosfer bumi. Solar Constant (konstanta surya) $\mathrm{Gsc}=1367 \mathrm{~W} / \mathrm{m} 2$ (World Radiation Center (WRC)) merupakan energi dari matahari setiap satuan waktu yang diterima suatu satuan area permukaan tegak lurus dengan arah perambatan radiasi pada jarak rata-rata bumi-matahari, di luar atmosfer. Matahari bisa menjadi sumber energi yang sempurna untuk menyediakan tenaga listrik yang diperlukan di seluruh dunia. Sayangnya energi yang berasal dari matahari tidak bersifat homogen. Nilai segeranya tidak saja bergantung kepada cuaca setiap hari, namun berubah-ubah sepanjang tahun. Artinya, energi yang tersedia untuk mengoperasikan peralatan listrik juga akan berubah-ubah. Setiap hari matahari terbit di timur dan ketika semakin meninggi di langit, maka volume energinya meningkat hingga mencapai puncaknya pada tengah hari (setengah rotasi antara terbit dan terbenam). Setelah itu (pada saat matahari bergerak ke arah barat), energi yang tersedia berkurang. Efek lain yang kita perlu ingat adalah bahwa bumi mengitari matahari sepanjang tahun. Hal ini berada di belahan bumi selatan (dan tidak berada di garis katulistiwa), maka anda akan mengalami musim dingin, oleh karena jalur matahari akan rendah di ufuk utara. Sebaliknya pada saat musim panas, matahari akan berada pada jalur tinggi di ufuk utara. Anda yang berada di belahan bumi utara akan menyaksikan matahari 20 mengikuti jalur yang sama tetapi di ufuk selatan. Hal ini terjadi karena bumi mengitari matahari, maka dampaknya pada bumi adalah matahari mengikuti jalurnya. (Vries DKK, 2011).

\section{PENYERAPAN SINAR MATAHARI}

Penyerapan sinar matahari oleh sebuah kolektor surya tergantung dari jenis kolektor tersebut dan sudut terhadap matahari' dengan mengatur sudut kemiringan kolektor maka daya serap dapat dilihat seperti persamaan berikut :

$$
\begin{aligned}
\cos \theta= & \sin \delta \cdot \sin \phi \cdot \cos \beta-\sin \delta \cdot \cos \phi \cdot \sin \beta \cdot \cos \gamma+ \\
& \cos \delta \cdot \cos \phi \cdot \cos \beta \cdot \cos \omega+ \\
& \cos \delta \cdot \sin \phi \cdot \sin \beta \cdot \cos \gamma \cdot \cos \omega+ \\
& \cos \delta \cdot \sin \beta \cdot \sin \gamma \cdot \sin \omega
\end{aligned}
$$

Jika besar energi yang diterima dinding Trombe vertical dan horisontal berbeda, maka temperatur permukaan dinding Trombe juga akan berbeda, sehingga besar perpindahan panasnya pun akan berbeda pula, sesuat dengan persamaan Newton tentang konveksi

$$
\begin{aligned}
\dot{Q}_{\text {conv }} & =h A\left(T_{s}-T_{\infty}\right) \\
\mathrm{h} & =\text { koefisien perpindahan panas } \\
\mathrm{A} & =\text { luas permukaan } \\
\mathrm{T} & =\text { temperatur }
\end{aligned}
$$

Dalam analisis tentang konveksi alami, perlu diketahui parameter-parameter seperti angka Grashof ( $\mathrm{Gr}$ ), angka Prandtl (Pr), angka Rayleigh ( $R a)$, dan angka Nusselt, dimana : 


$$
N u=\frac{h \delta}{k}=C(G r \cdot \operatorname{Pr})^{n}=C \cdot R a^{n}
$$

Untuk plat vertikal, nilai angka Nusselt adalah:

$$
N u=\left\{0,825+\frac{0,387 R a^{1 / 6}}{\left(1+(0,492 / \mathrm{Pr})^{9 / 16}\right)^{8 / 27}}\right\}_{6)}
$$

Untuk plat horisontal dengan permukaan atas lebih panas, nilai angka Nusselt adalah :

$$
\begin{aligned}
\mathrm{Nu} & =0,15 \mathrm{Ra}^{1 / 3} \\
\mathrm{Gr} & =\text { angka Grashof } \\
\mathrm{Pr} & =\text { angka Prandtl } \\
\mathrm{Ra} & =\text { angka Rayleigh }
\end{aligned}
$$

\section{PEMAKAIAN BATU ALAM}

Kerajinan batu alam makin banyak dicari untuk hiasan interior maupun ekseterior hunian, hotel maupun apartemen. Efek yang ditimbulkan ruangan menjadi lebih mewah namun nyaman dan alami. Kini produk yang ditawarkan dan jenis batu yang digunakan pun makin beragam. Pesona batu alam sebagai bagian dari interior hunian yang terkesan artistik dan alami membuat bahan ini banyak dicari untuk menimbulkan efek minimalis. Batu alam yang kerap digunakan diantaranya seperti andesit, basalto,marmer,granit, travertine, onyx, limestone, hingga sandstone atau paras. Selain untuk dinding ruangan, bahan baku batu alam juga kini makin banyak diaplikasikan untuk bagian rumah lainnya, seperti lantai, lantai, tiang, wastafel, hingga bath tub. Banyak perajin batu alam mengkreasikan batu alam untuk produk lainya seperti lampion taman, relief, hiasan taman, dan lainnya.( Majalah Kontan 26 Oktober 2015 ).

\section{METODE PENELITIAN}

Penelitian ini diawali dngan kajian pustaka untuk melihat beberpa penelitian terdahulu yang berkaitan dengan pemanfaatan sinar matahari untuk pengkondisian ruangan , kemudian diputuskan untuk melakukan kajian menggunaka dinding Trombe yang terbuat dari batu alam NTT.

Dalam penelitian ini akan dibandingkan kondisi udara pada tiga macam bentuk ruangan, yaitu ruangan tanpa dinding Trombe, ruangan dengan dinding Trombe vertikal, dan ruangan dengan dinding Trombe horisontal. Dimensi ruangan yang dibuat adalah $1 \mathrm{~m} 3$, dengan tinggi $1,5 \mathrm{~m}$, dengan berbahan rangka kayu dan dinding ruangan terbuat dari styrofoam dengan ketebalan $3 \mathrm{~cm}$, kaca penutup dengan ketebalan $5 \mathrm{~mm}$. Dinding Trombe berdimensi $1 \times 0,8 \mathrm{~m}$, dengan ketebalan $8 \mathrm{~cm}$, berbahan batu alam dari TTS NTT. Untuk menghindari adanya konveksi panas dari dinding ke dalam ruangan, maka pada bagian dalam dinding diisolasi panas dengan styrofoam. Adapun skema instalasi penelitian ditampilkan pada gambar 3.1 . Penelitian dilakukan di laboratorium Konversi Energi Politeknik Negeri Kupang. Waktu penelitian adalah pada bulan Juni, sampai November dan data yang ditampilkan adalah data pada bulan November. Kondisi udara yang diamati adalah temperatur dan kelembaban relatif (relative humidity) pada ketiga ruangan, dan akan dibandingkan dengan kondisi udara luar. Pengamatan dilakukan selama 10 jam dari jam 7 pagi, dan kecepatan pengambilan data yaitu tiap 5 menit. Untuk memperbesar beda temperatur antara udara masuk dan udara keluar, maka pada saluran masuk diberi reservoir air, dengan tujuan menurunkan temperatur udara masuk. Reservoir air ini dalam kondisi tertutup, dengan tujuan untuk menghilangkan penambahan kandungan air pada ruangan, yang nantinya akan menambah kelembaban ruangan. Untuk membantu aliran massa, maka pada ruangan diberi cerobong, dengan tujuan memperbesar selisih elevasi antara saluran masuk dan saluran keluar, yaitu elevasi sebesar 1,35 cm. Dengan adanya beda elevasi yang makin besar maka beda tekanan udara akan makin besar pula, yaitu sebesar $15,6 \mathrm{~N} / \mathrm{m} 2$. Alat ukur yang digunakan pada penelitian ini adalah piranometer sebagai alat ukur radiasi matahari, dan sensor LM35 sebagai alat ukur temperatur, dan dengan bantuan komputer sebagai sistem akuisisi data. Untuk mendapatkan kelembaban relatif udara, perlu diketahui temperatur bola kering dan temperatur bola basah, yaitu dengan membungkus sensor LM35 dengan kain kasa basah. Untuk mengetahui temperatur permukaan dinding Trombe, maka pada dinding akan ditanamkan 2 sensor LM35 pada kedalam 2 dan $4 \mathrm{~cm}$, kemudian dengan regresi linier akan dihitung temperatur permukaannya. Setelah didapatkan temperatur bola kering dan bola basah, maka data tersebut akan dimasukkan ke dalam perangkat lunak ASHRAE psychrometric calculator untuk mendapatkan sifat-sifat udara masing-masing. Untuk mengetahui tingkat kenyamanan udara, maka pada penelitian ini juga menggunakan diagramkenyamanan 
udara untuk manusia



Gambar 4. System dinding trombe yang digunakan.

\section{LOKASI PENELITIAN}

Pembuatan dinding Trombe akan dipesan pada tempat pembuatan Meubel agar ukuran bahannya lebih akurat sesuai ukuran yang ditentukan, sedangkan pengujian akan dilakukan pada Laboratorium Konversi Energi Politeknik Negeri Kupang.

\section{Variabel Bebas :}

\section{VARIABEL PENELITIAN}

1. Ukuran dinding dan ruangan dinding Trombe

2. Posisi vertikal dinding Trombe

3. Waktu pengamatan

\section{Variabel Bergantung :}

Temperatur luar dan dalam ruangan dengan dinding Trombe

Variabel Kontrol trombe

Temperatur ruangan tanpa dinding

\section{Alat dan Bahan}

Alat-alat uji terdiri dari 2 buah ruangan uji yaitu ruang uji dengan dinding Trombe yang Vertikal, yang kedua yaitu ruang uji tanpa dinding Trombe.

Bahan yang digunaka yaitu rangka ruangan dari kayu dengan penyerap panas dari batu alam NTT yang dibeli di pasaran, dengan penutup kaca $5 \mathrm{~mm}$ dan penutup ruang dalam dari stirofoam.

Alat ukur yang digunakan yaitu :

1. Sofware ASHARE Psycometric calculator

2. Piranometer

3. Sensor panas LM35

4. Arduino UNO untuk pasang sensor

\section{HASIL DAN PEMBAHASAN}

Dari penelitian yang dilakukan pada Bulan Januari 2018 didapatkan data radiasi matahari untuk bidang horisontal dan data temperatur pada tiap titik pada ketiga ruang, serta data udara luar. Radiasi matahari yang menembus kaca pelapis akan memanaskan permukaan dinding Trombe, sehingga temperaturnya akan berubah-ubah seperti yang ditampilkan



Gambar 5. Grafik Hasil Penelitian

Hasil penelitian menunjukkan bahwa pada pukul 09 sampai 12.00 , suhu ruangan dengan dinding Trombe dan suhu ruangan tanpa dinding Trombe cenderung sama dengan suhu udara luar karena matahari saat itu bertambah panas dan sistem dinding 
Trombe belum berfungsi karena suhu penyerap panas belum tinggi atau masih sama dengan suhu udara luar yaitu $33^{\circ} \mathrm{C}$. pada pukul 13.00, suhu penyerap panas dinding dinding trombe meningkat hingga mencapai $47^{\circ} \mathrm{C}$ pada pukul 14.00 sehingga menyebabkan aliran udara dalam ruangan mengalir kencang dan sekaligus menurunkan suhu ruangan. Penurunan suhu ini terus berlangsung dari pukul 14.00 sampai pukul 21.00. jika dibandingkan antara ruangan dengan system dinding trombe dan ruangan tanpa system dinding trombe maka didapatkan bahwa rata-rata suhu ruangan menurun antara $1^{\circ} \mathrm{C}$ sampai $2^{\circ} \mathrm{C}$, ini cukup signifikan namun hanya sampai pukul 21.00 karena saat itu suhu penyerap panas dan celah dinding antara kaca dan penyerap panas sudah rendah.

Hasil yang didapatkan pada grafik diatas cukup baik namun jika dibandingkan dengan standar kenyamanan manusia maka hal itu belum tercapai karena suhu standar kenyamanan manusia yaitu antara $21{ }^{\circ} \mathrm{C}$ sampai $25{ }^{\circ} \mathrm{C}$. hal ini disebabkan karena suhu udara rata-rata di NTT pada bulan Januari cukup panas yaitu antara $27{ }^{\circ} \mathrm{C}$ sampai $34^{\circ} \mathrm{C}$.

\section{PENUTUP}

Kesimpulan :

1. Pemakaian sistem dinding trombe dengan penyerap panas batu alam Pulau Timor dapat menurunkan suhu ruangan

2. Penurunan suhu yang didapatkan belum memenuhi standar kenyamanan manusia.

Saran :

Penelitian dilakukan pada bulan September sampai Oktober dimana suhu udara panas di NTT mencapai puncaknya agar dapat diketahui keadan suhu dengan pemakaian dinding Trombe

\section{DAFTAR PUSTAKA}

Brown, GZ. De Kay, Mark. 2001. Sun , wind, and light, architectural design strategies. 2nd edition.New York. John Wiley and Sons.

Cengel, Yunus A. 2003. Heat transfer a practical approach. 2nd edition. McGraw Hill. New York

Duffie, John A. dan Beckman, Willium, A. 1980, Solar engineering of thermal process, New York, John Willey \& Sons

Febrita, Yuswinda. 2011. Ventilasi Solar Cimney Sebagai Alternatif Desain Passive Cooling di Iklim Tropis Lembab (Jurnal).

Jansen, Ted J. 1995. Teknologi rekayasa surya. Terjemahan Wiranto Arismunandar. PT. Pradnya Paramita Jakarta

Kaewruang, Sirisak. 1997. Feasibility Study of Using Trombe Wall Towards Natural Ventilation of Houses Under Hot and Humid Climate. School of energy and materials. King Mongkut's Institute of Technology Thonbury, Thailand

Kalogirou, Soteris. 2009. Solar energy engineering. 1st edition. Elsevier. USA

Koyunbaba, Basak Kundacki. dan Yilmaz, Zerrin. 2012. The Comparison of Trombe Wall Systems with Single Glass, Double glass and PV panels.

Neville, Richard C. 1995. Solar energy conversion 2 nd edition. Elsevier

Ong, KS. dan Chow, CC. 2003. Performance of a solar chimney. Solar energy vol.74

Quaschning, Volker. 2005. Understanding renewable energy systems. Carl Hanser

Verlag $\mathrm{GmbH}$ \& Co KG

Raman, P. dkk. 2001. A passive solar system for thermal comfort conditioning of buildings in composite climates. Solar energy vol. 70.

Ruiz, A. dkk. 2005. A calculation model for Trombe walls and its use as a passive cooling technique, International Conference "Passive and Low Energy Cooling for the Built Environment Santorini Greece.

Stoecker, W. F. 1982. Refrigeration and air conditioning. Edisi kedua. McGrawHill. New York

Sun, Wei., Ji, Jie., Luo, Chenglong., dan He, We. 2011. Performance of PV-Trombe wall in winter correlated with south facade Design (Jurnal).

Sudjito, S. 2009. Teknologi tenaga matahari proses termal. Universitas Brawijaya. 